\title{
The impact of digitalization on the social entrepreneurship development
}

\author{
Popov E.V. ${ }^{1}$, Veretennikova A.Y. ${ }^{2}$, Kozinskaya K.M. ${ }^{3}$ \\ Institute of Economics, the Ural branch of the Russian Academy of Sciences \\ Ekaterinburg, Russia \\ 1epopov@mail.ru, ${ }^{2}$ vay_uiec@mail.ru, ․ㅡssush1@yandex.ru
}

\begin{abstract}
The development of social entrepreneurship depends on many factors, such as the institutional environment, which includes the protection of property rights, strong support for structural changes, an effective education system, and also social security. However, technological changes are one of the important components of the economic development of society. Information processing systems and digital-related activities are now invading almost every single aspect of the business.

The study aim is to model the impact of the institutional environment digitalization on social entrepreneurship development in Europe countries. For the goal achievement, a regression analysis was carried out, factors affecting social entrepreneurship were identified, and a one-factor nonlinear model demonstrating revealed patterns was constructed. The information base of the study was the international reports GEM, EIDES. The authors of the study constructed a nonlinear one-factor model demonstrating the impact of physical infrastructure digitalization on social entrepreneurship at the operational phase of development. The significance of the results obtained lies in the possibility of using the identified patterns for social entrepreneurship development.
\end{abstract}

Keywords: social entrepreneurship, digitalization, institutional environment.

\section{INTRODUCTION}

Globally, social entrepreneurship has received increasing attention in recent decades. This process can be explained by complementary economic, social, and political changes. On the one hand, problems persist that require innovative approaches to solving (i.e., on the demand side), on the other hand, development increases the chances of solving problems (i.e., on the supply side).

However, studies of the institutional environment of social entrepreneurship lag behind the practice. The study of this phenomenon is, as a rule, fragmented, and of an unsystematic character. If studies on the institutional environment of social entrepreneurship are found often [1], there are no studies dedicated to the digitalization level in these institutions and its impact on the development of social entrepreneurship. At the same time, digitalization is an essential condition for the development of the institutional environment of social entrepreneurship. Digitalization helps to reduce transaction costs, quickly obtain the necessary information, mobility, and the emergence of new ways to get support, such as crowdfunding, which is especially important for entrepreneurs who are limited in resources [2].

\section{THE MAIN DEFINITIONS}

A. The social entrepreneurship definition.

In scientific research, there is no standard definition of social entrepreneurship. Social entrepreneurship can have a multidimensional dynamic design. The main difference between social entrepreneurship and classical entrepreneurship is on the priority of creating social wealth, rather than economic welfare. While in commercial entrepreneurship, the creation of social wealth is a side effect, in socially-oriented activities, the main emphasis is on creating social value. However, this does not mean that social entrepreneurship should not receive income from its activities; on the contrary, additional income provides economic stability and financial self-sufficiency. 
Another hallmark of social entrepreneurship is limited opportunities for economic benefits. Thus, social entrepreneurship is a type of classical entrepreneurship that has a shift in the primary goal of its activities: from commercial to social, but profit is not only not excluded, but also necessary for the functioning of the organization. Since social entrepreneurship is a subset of traditional entrepreneurship and complements it, the differences between them are not dichotomous, but rather, entrepreneurship varies from purely social to purely commercial [3].

In the research, by social entrepreneurship, we mean a set of interrelated activities aimed at solving social problems by developing the commercial activities of economic agents [4]. It should be noted that the rapid invasion of digital technologies affected not only production processes but also the system of existing institutions, which plays a key role in the development of social entrepreneurship.

\section{B. Digitalization}

Digitalization is the process by which digital technologies and infrastructures get woven into the fabric of the economy and society [5].Digitalization can also bring new business opportunities, change the roles of operators in the value chain, and put an end to the existing business. For example, digitalization can remove traditional intermediates in the supply chain and create new intermediates.

As a modern trend in the development of the global economy and society, digitalization in different countries has different effects. The place of each country in the world community depends on the degree of impact of digitalization on national economic and social life.

Over the recent decade, entrepreneurship has undergone a global transformation. The entrepreneurial opportunities were radically redefined, and the practices to pursue them have changed accordingly. These transformations are reflected in the global adoption of new organizational innovations to support entrepreneurial activity, and above all in the emergence of a regional agglomeration of economic activity: the entrepreneurial institutional environment [6]

\section{Institutional environment}

There is much evidence of the impact of institutions on economic growth. According to the concept of D. North, the central role of institutions in society is to reduce uncertainty by establishing stable structures for people interaction. They consist of both informal restrictions (values, norms, prohibitions, customs, traditions, and codes of conduct), and formal rules (constitution, laws, economic rules, property rights and contracts) [7].W. Scott divided all the institutions of entrepreneurship on regulatory, supportive, and cognitive. Most formal of these are regulatory institutions. They are norms which are attributed in regulatory legal acts. Supporting institutions are less formal, cultural, and cognitive institutions are the most informal and exhaustive rules and beliefs, established between individuals and their social interaction [8].

The regulatory environment refers to "formal rules and incentives that limit and regulate entrepreneurial behavior" [9]. The formal institutional environment is responsible for establishing rules, rewards, or punishments. As entrepreneurs in emerging markets face rapid institutional changes associated with changes in the economic climate, levels of government participation, ownership structures, and regulatory support, the regulatory environment has a significant impact on the activities of social entrepreneurs Researchers C. Seelos, J. Mair, $\mathrm{J}$. Battilana found that regulatory factors exercise control over the processes and results of socially oriented activities [9].

The need to consider the informal institutional environment in the analysis of social entrepreneurship is primarily due to the importance of social ties for the development of this type of activity. According to the theory of C. Williamson, restrictions range from attitudes, beliefs, customs, norms, and traditions that govern the behavior of individuals to private judicial systems [11]. S. Peyovich develops the theory of C. Williamson, also pointing to such signs of informal institutions as the spontaneity of occurrence and features of sanctions [12]. 
A supportive environment plays an essential role in determining and shaping entrepreneurial results [9]. Supporting mechanisms arise from social structures and are responsible for the formation of adequate entrepreneurial behavior.

\section{METHODOLOGY}

\section{A. Data Sources and Hypothesis}

The European Index of Digital Entrepreneurship Systems, presented in the paper, responds to the need for a tool to better understand and appraise the extent of the digital entrepreneurial institutional environment for social entrepreneurship as a subset of classic entrepreneurship.

The structure of the revised EIDES encompasses four pillars for the General Framework Conditions (i.e., Culture and Informal Institutions, Formal Institutions, Regulation, and Taxation, Market Conditions, and Physical Infrastructure) and their associated digital counterparts. Specifically, each framework condition can be digitalized with a suitable measure of a corresponding digital context obtained made by variables that reflect the digitalization of each specific framework condition. Consequently, two versions of each framework condition appear in the index: a non-digitalised version and a digitalized one. In the research, we have used EIDES report because it measures digitalization institutional environment affecting entrepreneurship in general.

As for a formal institutional environment, at EIDES, the formalization, taxation, and taxation component of digitalization includes several metrics describing digital security and privacy. This pillar also includes proxies that measure how formal institutions and the regulatory environment shape digitization and competition. Reliance also reflects the digitization of public services, with an emphasis on e-government. Regarding the informal institutional environment, it should be noted that the digital pillar, which complements the general column of culture and informal institutions, includes proxies that show how easily citizens and enterprises can use their country's digital infrastructure. For measuring the supportive institutional environment, we used market condition index and physical infrastructure index from EIDES report. The digital counterpart of the Market Conditions pillar characterizes the exploitation of online market channels by adopting digital technology, households and businesses can enhance efficiency, reduce costs, and better engage customers, collaborators, and business partners [6]. Digitalization affected Physical Infrastructure pillar encompasses indicators reflecting quality-related features - such as affordability, speed, security, and coverage - of the digital infrastructure.

To evaluate social entrepreneurship, we reviewed the data presented in the report Global Entrepreneurship Monitoring. GEM is a global entrepreneurship research conducted by the university association. When determining the influence of the presented factors on social entrepreneurship, the indicator of the development of social entrepreneurship at the stage of start-up and operational activities, given in the GEM report, was used as a dependent variable [7].

In order to further modeling the impact of the digitalization level of the institutional environment on social entrepreneurship, two hypotheses were formulated:

Hypothesis 1. The digitalization level of the institutional entrepreneurship environment has a positive influence on the development of social entrepreneurship at the startup phase.

Start-up companies are newly born companies which struggle for existence. Social entrepreneurship deals with an idea, creativity, innovation, new product or service development, opportunity and needs a stable, effective, and innovative institutional environment, especially in the early stages of its development. Social entrepreneurship at the stage of formation requires quick access to all necessary information, the absence of additional costs for registering a socially oriented company, the ability to use Internet resources to search for additional support opportunities.

Hypothesis 2. The digitalization level of the institutional entrepreneurship environment has a positive influence on the development of social entrepreneurship at the operational phase.

Social entrepreneurship at the stage of its functioning and development also needs developed 
institutions in terms of digitalization. Thus, free access to the market, provided by means of technological platforms and transparency of information, ensures sustainable development for social entrepreneurs.

\section{B. Study Procedure}

In analyzing the impact of digitalization of the institutional environment on social entrepreneurship, other factors from the report, such as "finance" and "networking and support," were also analyzed. However, they showed no significant correlation and were removed from the study.

Also, we initially examined the performance of European countries for which data are available in the GEM and EIDES report (23 countries). However, then we excluded Eastern European countries from analysis because the development of formal and supporting institutions in these countries is in its infancy and does not significantly affect the development of social entrepreneurship. Thus, 14 countries remain in the model.

When constructing the model, a preliminary analysis of the initial statistical data was made, as a result of which the most suitable type of functional dependence between the considered economic processes was revealed.

\section{RESULTS}

For testing the hypotheses formulated and further simulate the impact of institutionalization digitalization on social entrepreneurship, the following dependent variables were considered:

- $\quad Y_{1}-$ share of the population engaged in social entrepreneurship in a particular country at the startup stage;

- $Y_{2}$ - share of the population engaged in social entrepreneurship in a particular country at the stage of operational activity. Independent Variables:

- $\quad X_{1}$ - formal institutions;

- $X_{2}$ - market condition;

- $X_{3}$ - physical infrastructure;

- $X_{4}$ - informal institutions.

However, due to the fact that the correlation between the development of social entrepreneurship at the start-up stage and factors turned out to be extremely weak, the regression coefficients are insignificant, and also not theoretically confirmed, they were excluded from further analysis. Thus, hypothesis 1 was not confirmed.

At the initial stage of the data analysis, it was revealed that the distribution of random variables for the tested factors and the dependent variable $\mathrm{Y}$ is nonlinear. The distribution takes the form of a power law. In this regard, the initial data were converted into a nonlinear form, and then a nonlinear regression model was constructed. After eliminating the factors that do not have a significant impact based on testing the hypothesis of the insignificance of the regression coefficients, the dependence of the level of social entrepreneurship on factor $X_{3}$ was established. After conversion, this model was presented in the following form:

$Y_{2}=\mathrm{e}^{-1.31} \times X_{3}^{0.03}$

At the next stage, the adequacy and reliability of the results are evaluated. The significance of the coefficient of determination $\left(F_{\text {statistic }}=0.021\right)$ allows us to conclude that the model as a whole is reliable, and also confirms the representativeness of the sample. The determination coefficient $R^{2}=0.36$ indicates that the variation in the indicators of development of social entrepreneurship by approximately $36 \%$ depends on the indicators selected at the stage of modeling the matrix of pair correlation coefficients. Testing the null hypothesis of the insignificance of the regression coefficients showed that the selected factors do have an effect; their regression coefficients are statistically significant. The value of the Fcriterion and the significance level $p$ demonstrate that the constructed model is significant at the significance level $\mathrm{a}=0.05$. The DarbinWatson test used to test the model for the presence of autocorrelation of residues $\left(d_{\text {calc }}=1.95\right)$ showed that there is no relationship between the residues, and they are random. 


\section{DISCUSSION}

The analysis showed that the impact of digitalization of the institutional environment on the emergence of social entrepreneurship is negligible. It may be due to the fact that this process is influenced by other important factors, such as state support, financial support instruments, and socio-cultural characteristics in society. Thus, the digitalization of institutions does not affect the moment when social entrepreneurship enters the operational stage, and here digital infrastructure begins to influence its development, expressed in such indicators as the quality of Internet connection, its coverage, and Internet access. Since social entrepreneurship is innovative in its search for solutions to the social problems of society, the accessibility, speed, and quality of communication and communication channels, primarily through the Internet and mobile communications, is an essential criterion for it. At the same time, the impact of infrastructure digitalization was shown in all studied European countries, except for the countries of Eastern Europe. The reason for this observation may lie on historical features of the development of social entrepreneurship in these countries. There are institutions with a more significant negative impact on the development of this phenomenon. This issue is a topic for further research on social entrepreneurship.

The significance of the presented study is to justify the need to take into account the digitalization of the institutional environment in the study of social entrepreneurship. This study can be developed by taking into account the addition of factors describing the digitalization of the institutional environment, as well as factors determining this influence in different groups of countries.

\section{REFERENCES}

[1]. Stephan U., Uhlaner L., Stride C., Institutions and social entrepreneurship: the role of institutional voids, institutional support, and institutional configurations, Journal of International Business Studies, 2015, vol. 3 (46). pp. 308-331.

[2]. Frach L., Fehrmann T. Digital Government. [S.1.,] 2017.

[3]. Mair J. Social Entrepreneurship Research: A Source of Explanation, Prediction, Journal of world business, 2006, vol. 1, p. 7389.

[4]. Popov E., Veretennikova A., Kozinskaya K. Social entrepreneurship as an object of institutional analysis, Vestnik Permskogo universiteta. Ser. Ekonomika. $=$ Perm University Herald. Economy, 2017, vol. 12, no. 3, pp. 360-374.

[5]. Autio E. Digital Affordances, Spatial Affordances, and The Genesis of Entrepreneurial Ecosystems, Forthcoming in the Strategic Entrepreneurship Journal, 2018, vol. 12, no 1.

[6]. The European Index of Digital Entrepreneurship Systems. Available at: https://ec.europa. $\mathrm{eu} / \mathrm{jrc} / \mathrm{en} /$ publication/european-indexdigitalentrepreneurship-systems.

[7]. GEM 2015 Report on social entrepreneurship. Available at: https://www.gemconsortium. org/report/gem-2015-report-onsocialentrepreneurship.

[8]. North D. Institutions, Institutional Change and Economic Performance. Cambridge: Cambridge University Press, 2014. p. 267.

[9]. Scott W. Institutions and organizations. ThousandOaks, CA: Sage, 2014

[10]. [10] Seelos C., Mair J. The embeddedness of social entrepreneurship: understanding variation across local communities, Research in the Sociology of Organizations, 2011, vol. 33, pp. 333-363.

[11]. Dees J. Framing a theory of entrepreneurship: Building on two schools of practice and thought, in ARNOVA Occasional Paper Series: Research on Social Entrepreneurship: Understanding and Contributing to an Emerging Field, 2006, p. 39.

[12]. Gartner W. A conceptual framework for describing the phenomenon of new venture creation, Academy of Management Review, 1985, vol. 10, no 4, pp. 696-706. 